\title{
Los desafíos competenciales del DirCom venezolano identificados en LCM 2016 -2017
}

\section{The Competential Challenges of Venezuelan DirCom identified in LCM 2016 -2017}

\section{Os desafios competitivos da DirCom venezuelana identificados no LCM 2016 -2017}

\author{
Xiomara Yamil Zambrano ${ }^{1}$ \\ Universidad Católica Andrés Bello (Venezuela) \\ xzambran@ucab.edu.ve \\ Claudia Furiati Páez ${ }^{2}$ \\ Centro de Investigaciones de la Comunicación (Venezuela) \\ forum.media.services@gmail.com \\ Ángeles Moreno ${ }^{3}$ \\ Universidad Rey Juan Carlos (España) \\ mariaangeles.moreno@urjc.es
}

Fecha de recepción: 06 de febrero de 2018

Fecha de recepción evaluador: 30 de septiembre de 2018

Fecha de recepción corrección: 06 de noviembre de 2018

\footnotetext{
1 Xiomara Yamil Zambrano es Doctora en Ciencias Sociales (UCV) con amplia trayectoria en Comunicación Organizacional, Responsabilidad Social, activismo empresarial en Venezuela.

2 Claudia Furiati Páez es Comunicadora Social venezolana (UCV) con especialización en Comunicaciones Integradas (UNIMET). Es Investigadora Asociada del CIC-UCAB.

3 Ángeles Moreno es doctora con premio extraordinario por la Universidad Pontificia de Salamanca y Profesora Titular en la Facultad de Comunicación de la Universidad Rey Juan Carlos. https://orcid.org/0000-0002-0777-2957
} 


\title{
Resumen
}

La adecuación del perfil competencial del DirCom venezolano enmarcado en la dimensión de la comunicación inteligente es definida en este trabajo a partir del cruce del análisis de datos del estudio bienal Latin American Communication Monitor 2016-2017 (LCM), con enfoques teóricos transdiciplinarios que interpretan los desafíos que implica desempeñarse con éxito y ética en la era digital. Tal aproximación se contextualiza en el entorno de Venezuela, donde los actores del campo comunicacional, incluyendo al profesional, deben producir soluciones sociales a la crisis nacional en medio de la hegemonía de un "Estado-comunicador" y un gran entramado de encrucijadas del sector. Entre las más complejas estaría la imposición de políticas públicas, desinversión privada, debilitamiento de la sinergia entre academia y sociedad civil, e incremento de la emigración del talento. Se propone una innovación curricular que toma elementos del Marco Comparativo de Excelencia (CEF por sus siglas en inglés) planteado en LCM, integrándolos con el desarrollo de habilidades "blandas" mediadoras e influenciadoras y de destrezas "duras" en manejo de tecnologías móviles de cuarta generación como big data y algoritmos automatizados en redes sociales.

Palabras clave: competencias, excelencia, alfabetización digital, big data, ética, inclusión relacional

\begin{abstract}
The adequation of the competence profile of the Venezuelan DirCom framed in the dimension of intelligent communication, is sketched in this research from the crossanalysis of data from the biennial study Latin American Communication Monitor 20162017 (LCM), with transdisciplinary theoretical approaches that interpret the challenges that are involved in perform successfully and ethically in the digital era. This approach is contextualized in the Venezuelan environment, where the actors of the communicational field, including the professional, should produce social solutions to the national crisis in the midst of the hegemony of a "Communicator-State", and also the challenged of a great network of "crossroads" of the public communication sector. Among them, the imposition of public policies, private divestment, weakening of synergy between academia and civil society, and increased emigration of talent. It proposes a curricular innovation that takes elements of the Comparative Framework of Excellence (CEF) developed in the research study LCM, integrating them with the development of mediating and influencing soft skills and hard abilities on mobile technologies of 4th generation as big data and automated algorithms in social networks.
\end{abstract}

Keywords: Capability, Excellence, Systemic literacy, Big Data, Ethics, Relational inclusion

\section{Resumo}

A adequação do perfil de competências da DirCom venezuelana, enquadrada na dimensão comunicação inteligente, é esboçada nesta pesquisa a partir da análise cruzada de dados do estudo bienal Latin American Communication Monitor 2016-2017 (LCM), com 
abordagens teóricas transdisciplinares que interpretar os desafios envolvidos no desempenho com sucesso e ética na era digital. Essa abordagem é contextualizada no ambiente venezuelano, onde os atores do campo comunicacional, incluindo o profissional, devem produzir soluções sociais para a crise nacional em meio à hegemonia de um "Estado Comunicador", e também o desafio de uma grande rede de "encruzilhada" do setor de comunicação pública. Entre eles, a imposição de políticas públicas, o desinvestimento privado, o enfraquecimento da sinergia entre a academia e a sociedade civil e o aumento da emigração de talentos. Propõe uma inovação curricular que utiliza elementos do Quadro Comparativo de Excelência (CEF) desenvolvido no estudo de pesquisa LCM, integrando-os com o desenvolvimento de mediação e influência de soft skills e hard skills em tecnologias móveis de quarta geração como big data e algoritmos automatizados nas redes sociais.

Palavras-chave: Capacidade, Excelência, Literacia Sistémica, Big Data, Ética, Inclusão Relacional

\section{Introducción}

La realización del estudio bienal Latin American Communication Monitor 20162017 (LCM), en su segunda edición, coincide con el interés de la sociedad por abordar y comprender el avance de la llamada Cuarta Revolución Industrial (Schwab, 2015). En esta inquietud resalta el vínculo entre los fenómenos sociales y el desarrollo de las nuevas tecnologías en el campo de la información y procesamiento de datos, así como la emergencia de paradigmas gerenciales transformadores, incluyentes y relacionales.

Los hallazgos permitieron precisar diversas necesidades de atención para el profesional de la comunicación en 17 países de la región. Venezuela participó por vez primera en la consulta, mediante grupo de DirCom previamente seleccionados según perfil establecido por EUPRERA/DIRCOM, con el apoyo local del Centro de Investigación de la Comunicación de la Universidad Católica Andrés Bello (CIC-UCAB).

Además de las interrogantes centrales del estudio, el presente artículo agrega otras y parte de la hipótesis que supone una función de comunicación de excelencia en correspondencia al devenir estratégico de la organización, para responder con éxito ante fenómenos como el big data, la imposición de un "Estado-comunicador", así como otros aspectos propios de la economía global y local. Por ello, el comunicador en toma de decisiones ha de requerir un acoplamiento de su desempeño.

La investigación se planteó responder a las siguientes preguntas:

¿Cómo es el perfil del DirCom venezolano, a la luz de los resultados del LCM?

¿Cuáles son las tendencias de la sociedad contemporánea y los elementos del entorno donde venezolano que pudieran incidir en el desempeño del DirCom?

¿Cuáles son los desafíos a tener en cuenta para su desempeño, de acuerdo a los criterios de excelencia comunicacional? 
¿Hay correspondencia entre oferta académica de cuarto nivel en Venezuela con esos desafíos?

¿Cuáles son los elementos necesarios para trazar las bases de un perfil competencial en mallas curriculares de posgrado como herramienta para la transformación de los DirCom venezolanos según el modelo de comunicación excelente?

Tanto de la interpretación las respuestas derivadas del análisis de cara a resultados del LCM en Venezuela, como el procesamiento y valoración de datos considerados en la contextualización, así como la revisión teórica de relevancia, al cierre del texto se proponen cinco ejes paradigmáticos de actualización del perfil de capacitación del comunicador. El modelo esbozado articula habilidades blandas y duras, transdiciplinarias, integradoras y generadoras de una alfabetización sistémica (Goleman, 2013, p.189) y de apropiación estratégica del conocimiento asociado a la revolución digital, siendo en un 95\% los consultados emigrantes analógicos. En suma, se aspira hacer del comunicador un sujeto consciente de su rol de co-creador de múltiples realidades y de influenciador calificado en el ecosistema social del siglo XXI.

\section{Marco referencial | Contexto de estudio}

El ambiente profesional y personal para el comunicador social en Venezuela es un contexto signado por el incremento sostenido y constante de la complejidad política, económica y social, el cual demanda sostenidos esfuerzos para su comprensión y desarrollo de estrategias y planes de acción. Ello se refleja en la acentuada inherencia de un sistema de gobierno central en los espacios de la vida pública, y progresivamente, de la privada, cuyo eje simbólico es el binomio que conforman las figuras de Simón Bolívar y Hugo Chávez. Uno de sus principales rasgos a lo largo de casi dos décadas, ha sido la ocupación del territorio ideológico de lo social, comunicacionalmente estructurado bajo la identidad de "Misiones", protagonizadas por miembros de organizaciones comunitarias llamadas Consejos Comunales, designadas representantes directas del Poder Central ante otros actores sociales que hacen vida en un entorno urbano determinado (barrio, parroquia o municipio) (ILDIS, 2006).

A diferencia de sus países vecinos, con tendencia hacia la apertura e integración de sus mercados, así como la intensificación de la inversión privada y la cooperación trisectorial (Estado, empresariado y sociedad civil), la República Bolivariana de Venezuela ha ido cerrando su interacción financiera con la región y con la economía global, a excepción de naciones como Rusia y China, aliadas comerciales e ideológicas. El país ocupa el puesto 179, de 180, en el índice global de Libertad Económicaii (Miller \& Kim, 2016), y otros indicadores dan cuenta de su merma económica: inflación de 274,4\% en 2016 y un decrecimiento de 5,7 \% en 2015, según cifras del Banco Central de Venezuela. Sin embargo, la opacidad de data tanto en las estadísticas como en memorias y reportes de gestión en la administración pública nacional, han conducido tanto a la comunidad científica como a distintos actores demandantes de información oficial, al uso de fuentes alternas y confiables de consulta generadas por entes multilaterales, centros especializados, ONG's o consultoras privadas. 
En materia de bienestar, el país obtuvo en 2016 una calificación de 62,60 puntos en Índice de Progreso Social (Global Progress Initiative, 2016), disminuyendo casi 1 punto con relación a 2015. El estudio Análisis de las Condiciones de Vida del Venezolano, (Universidad Católica Andrés Bello, Universidad Central de Venezuela y Universidad Simón Bolívar, 2016), desarrollado por un equipo interdisciplinario de expertos en ciencias sociales, muestra cifras de notorio desmejoramiento, principalmente un $\mathbf{8 1 , 8 \%}$ de hogares en situación de pobreza. También se aportan indicadores de conflictividad social e incremento de la violencia, ocupando el puesto 143 de 163 en el Índice Global de Paz (Institute for Economics and Peace, 2017).

Otro fenómeno social que ha tomado visibilidad reciente, es la emigración venezolana. Aunque no existen cifras oficiales, estudios sobre el tema arrojan que más de dos millones de personas han abandonado el país en los últimos años. Sin ser concluyente, la investigación "La voz de la diáspora venezolana" (Páez, 2015) señala a factores como falta de oportunidades profesionales, inseguridad personal y crispación social como los argumentos de base para que grupos de la población, en su mayoría con estudios de tercer y cuarto nivel, decidan marcharse. Se trata de un éxodo que además de afectar al aparato productivo, incide en la transformación de las relaciones sociales y culturales. Surgen nuevas formas de intercambio, de cooperación e incluso de trabajo, al fomentarse el empleo remoto ${ }^{\text {iii. }}$.

Es necesario mencionar como factor altamente relevante dentro de este análisis, a la contracción del sector privado formal. Según la Federación de Cámaras y Asociaciones de Comercio y Producción de Venezuela, Fedecámaras (2017), desde hace una década se observa una tendencia recesiva, con el cierre de aproximadamente 25 mil empresas por año. Los distintos entes patronales señalan fuerzas externas de toda índole, derivadas de un modelo económico y jurídico sustentado en la alta injerencia del Estado, mermando la competitividad de los negocios. Lo que ha crecido es el riesgo de expropiaciones e intervenciones a las empresas privadas, y en el caso particular de los conglomerados de medios de comunicación, se ha elevado el cese de concesiones (licencias) para el uso del espacio radioeléctrico (radio y tv), el control en la asignación de divisas a la prensa para la importación de papel, así como la penalización del ejercicio profesional de periodistas. La propiedad, en esos casos, es traspasada de facto a instancias gubernamentales, políticas o civiles vinculadas al oficialismo (Bisbal \& Aguirre, 2015; Pascuali, 2016). En contraposición a esta tendencia de "Estado-comunicadoriv", se han visto emerger consorcios multimedias y portales digitales de prensa independiente que buscan maniobrar fuera del ámbito del control estatal, así como la mayor concurrencia de la población al uso de las redes sociales como activo entorno para la "infociudadaníav".

A su vez, en el discurso ideologizante oficialista se reitera la tendencia a desprestigiar a la figura del empresario y al capital privado en general, así como al fomento de la conflictividad entre trabajador y patrono. Sin embargo, a pesar de esa manipulación semántica, distintos estudios dan cuenta de la valoración positiva y alta aceptación que tienen los actores del sector privado como proveedores de bienestar social. (Centro Gumilla, 2011; Venamcham, 2017). 


\section{La gestión venezolana en responsabilidad social}

Este posicionamiento positivo del empresariado venezolano dentro de amplio segmento de la población se debe en gran medida a sus políticas de la responsabilidad social y relacionamiento. Si bien se alinean a la visión global de progreso sostenible de las sociedades a partir de la ganancia compartida, existen notables diferencias con el resto de la región. A la ya referida práctica interventora del Estado en el negocio de naturaleza privada, se suman presiones mandatorias que convierten acciones sociales de carácter voluntario en instrumentos coercitivos e incluso penales. También aumentan las demandas de los grupos de interés clave de soluciones a sus urgencias o cobertura de necesidades básicas (alimentación, vivienda y salud). Más que un modelo de gestión acoplado a una estrategia de negocio para la creación de valor compartido (Kramer y Porter, 2011), y la integración trisectorial, la responsabilidad social tiende a ser reactiva. Lo cual hace inferir que predominan los estadios I y II de la responsabilidad social corporativa según el modelo planteado por Mirvis y Googins (2006). Las organizaciones se han volcado en la procura de un blindaje social, emocional, para contar con un margen de maniobra de orden afectivo, ante cualquier posible intento de expropiación o cierre, entre otras amenazas.

Este complejo escenario ha conducido a hacer de la gestión de responsabilidad social -campo que ocupan principalmente las unidades de asuntos públicos, relaciones públicas y/o comunicaciones de las empresas- una función en expansión. Al revisar el estudio Encuesta sobre Prácticas y Tendencias Actuales de la Responsabilidad Social y Ambiental en Venezuela, (Price Waterhouse, 2017), se identifica la gran influencia del clima social en la toma de decisiones del empresariado. E1 55\% de los consultados refiere a los factores externos como causales para la incorporación de la responsabilidad social al negocio, sin la aplicación de estándares internacionales. Las prácticas se orientan básicamente a atender requerimientos de sus públicos internos y comunidades, predominando la filantropía con un 61\%. En cuanto al ámbito comunicacional destacan las carencias de datos de inversión social ( $84 \%$ no tiene acceso), de mayores conocimientos sobre el campo y de una disposición a incrementar alianzas con grupos de interés activos en la cadena de valor.

\section{La encrucijada comunicacional}

Además de la breve revisión de los ámbitos político, económico y social como campos de permanente desafío para el comunicador en Venezuela, es imprescindible comprender el entorno comunicacional en el país, de una forma singular y desmarcada de las prácticas comunes a otros países de Latinoamérica. En la última década el sector ha vivido la instauración del "régimen comunicativo" o "nuevo orden comunicacional" como se autodefine desde la nomenclatura del poder y que se resume en los siguientes fenómenos:

"fuerte intervención estatal, hegemonía, exclusión de actores políticos y sociales en los medios gubernamentales, legislación que limita gravemente la libertad de expresión ${ }^{v i}$, eliminación de la disidencia comunicacional, cierre de fuentes informativas, límites al acceso de la información pública, generación de mecanismos reales de censura 
y autocensura, intimidación y agresión a medios y periodistas, exclusión publicitaria oficial para aquellos medios críticos y otras más". (Bisbal, 2012, p.12).

Tal confluencia entre acciones absolutistas desde el "Estado-comunicador" y vertiginosos cambios tecnológicos, que dificultan la gestión comunicacional venezolana, ha sido estudiada por investigadores de las universidades Central de Venezuela y Católica Andrés Bello, describiéndolo como un complejo sistema de siete encrucijadas (Bisbal \& Aguirre, 2015). La primera disyuntiva refiere a las políticas, economía y democratización de la comunicación aplicadas y que han resultado en poca transparencia en procesos de compra-venta de medios privados y en la desinversión publicitaria selectiva. La segunda, trascender el análisis del discurso del poder (Chavismo), dando cabida en el campo investigativo a otras problemáticas tales como las limitaciones al acceso a la información pública y el fortalecimiento de la contraloría ciudadana hacia los medios.

Como tercera intersección se expone la necesidad de unificar criterios en los estudios sobre consumo culturalvii, mediante una cartografía general que centralice las estadísticas sobre preferencias, exposición y prácticas (cuantitativo), así como la apropiación simbólica y mediación (cualitativo) entre los venezolanos y los medios. Se le suma un cuarto fenómeno, representado por la proliferación de los llamados medios

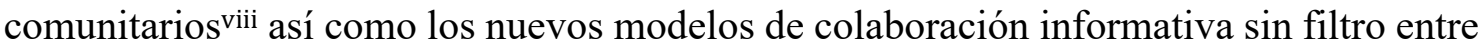
usuarios para temas ciudadanos, llamado "infociudadanía", cuya comprensión amerita consensuar conceptos y características.

Y vinculados más directamente a una actualización y fortalecimiento del perfil competencial del DirCom venezolano, razón de este artículo, se encuentran tres últimos dilemas más de la esfera del conocimiento (Bisbal \& Aguirre, 2015). El necesario fortalecimiento del campo investigativo de la responsabilidad social empresarial como bastión de la organización para practicar un relacionamiento transparente, confiable y sostenido con sus demandantes audiencias. El que atañe directamente al comunicador en formación, a ser perfilado como "el intelectual digital" (Delgado-Flores, 2006) responsable de una comunicación inteligente. Y finalmente, la procura de una mayor sinergia innovativa ${ }^{\text {ix }}$ que permita cartografiar y agendar políticas públicas, eventos, publicaciones, redes de intercambio y estudios empíricos. Para transitar con éxito cada uno de estos "derroteros" comunicacionales, desde la perspectiva del comunicólogo Antonio Pasquali (2016), profesional venezolano deberá anteponer sus principios morales y ontológicos, a la par que lidiar con la alfabetización digital, exigiendo transformarse es un "pequeño héroe cotidiano".

\section{La formación del comunicador organizacional en la Venezuela de hoy}

Desde hace más de una década, los trabajos de campo sobre la formación del comunicador social en Venezuela han venido ampliando la visión sobre su ámbito del desempeño, en atención a los desafíos que pauta transitar hacia una sociedad del conocimiento. En lo que refiere la línea organizacional, desde la academia se ha perfilado un arquetipo de profesionalización con competencias medibles enmarcadas en las teorías de capital humano (Alarcón García \& Guirao Mirón, 2013), y de gestión por desempeño en el ámbito laboral, amparados en el Proyecto Alfa Tuning América Latina 2004- 2007x. 
Sin embargo, estos planes de actualización de malla curricular, especialmente sobre la convergencia digital, se han hecho de forma atomizada las más de veces, entre las 14 universidades venezolanas que ofrecen carreras de comunicación social, organizacional y periodismo en el ámbito de pregrado y postgrado. De éstas destacan por su proyección continental a las públicas Universidad de Los Andes (ULA), Universidad Central de Venezuela (UCV), Universidad del Zulia (LUZ), así como las privadas UCAB, Universidad Monteávila, Universidad Santa Rosa y Universidad Cecilio Acosta.

De acuerdo a una exploración realizada por la ONG Investigadores Venezolanos de la Comunicación (Flores, 2017) en la oferta académica de estudios de tercer nivel en el territorio nacional, la formación en lo digital se circunscribe a cátedras que primordialmente refuerzan la orientación informativa de la profesión en conjunción con el manejo de nuevas herramientas web y aplicaciones (apps). El perfil del egresado en cuya malla curricular se detectan materias de gestión comunicacional vía TIC's, es hacia el manejo instrumental, en detrimento de una visión sistémica requerida para abordar el ecosistema de medios que emerge en la sociedad actual.

La consolidación del profesional para las comunicaciones integradas $\mathrm{u}$ organizacional es mayoritariamente diseñada en programas de cuarto nivel, en el que se instruyen en competencias de la gestión (la comprensión de las organizaciones, el contexto en el que operan y su gerencia); así como de las modalidades de mediación (interacción con los stakeholders) realzando su valor estratégico para la consolidación de una gestión viable, eficiente y sostenible. Así los postgrados venezolanos se han constituido en los "espacios de legitimación social en el proceso de estructuración científica del campo académico de la comunicación” (Canelón, 2012, p.10).

Sin embargo, seis de las ocho universidades que ofrecen estudios de cuarto nivel dedican parcialmente líneas de aprendizaje e investigación en manejo de herramientas y destrezas informacionales y de mercadeo y redes digitales. Las otras dos sí han elevado este campo del saber a rango de maestría en ciencias de la comunicación para desarrollo humano: la Universidad del Zulia y la Universidad Cecilio Acosta (Flores, 2017).

En caso de la Dirección de Postgrado en Comunicación Social de la Universidad Católica Andrés Bello, PostCom $\mathrm{UCAB}^{\mathrm{x}}$, en el presente adelanta acciones para una actualización curricular, a fin de incorporar transversalmente el pensamiento sistémico ${ }^{\mathrm{xii}}$ mediado por las tecnologías móviles. Se confirma que es propósito de esta instancia sumar la conciencia digital al actual perfil del egresado de su maestría, enfocado en manejo de cinco competencias generales: producción, interacción, cultura organizacional, acompañamiento, planificación y evaluación (Delgado-Flores, 2010). 


\section{Fundamentación teórica}

En el andamiaje de conceptos que amparan a la presente investigación, se privilegia el de la Comunicación Organizacional como fenómeno sistémico y complejo, que lleva a la organización a construir relacionamiento (engagement) ${ }^{\mathrm{xii}} \mathrm{y}$ mediación con sus stakeholders para sostener y dar transparencia a su imagen marca e institucional. Es la red de relaciones interdependientes que entreteje la empresa definida por Goldhaber (1999) en las que se suscitan intercambios de mensajes multimodales, integrados a través de una plataforma de estrategias, programas y dispositivos que sustenta el sistema de relacionamiento.

Los nuevos ecosistemas de medios imponen a las organizaciones trascender el esquema informacional y asumir con sentido estratégico las funciones de comunicaciones expresadas a través de la disciplina y práctica de la gestión relacional. Esto es dinamizar "experiencias comunicativas que se suceden con los públicos en un entramado de universos simbólicos, derivando en la construcción de capital social para la organización”. (Canelón, 2012, p.10)

Se propone entonces un profesional que pueda vivenciar y proyectar a la organización como "constructo humano con significados, hechos y eventos, y a la comunicación como concepto integral que posibilita relacionarse con los públicos, sus intereses y sus necesidades" tal y como postula Margarida Krohling (2009). El comunicador organizacional ha de cultivarse siguiendo patrones de capital humano y medición de desempeño. Canelón recurre al modelo de Alcover de la Hera, Martínez, Rodríguez y Domínguez (2004) para reunir los atributos de este perfil competencial idóneo: "saber" (disponer de conocimientos técnicos necesarios para la tarea); "saber hacer" (uso de los conocimientos a merced del despliegue de habilidades y destrezas); "saber estar" (desenvolverse de acuerdo a las normas y la cultura de la organización); "querer hacer" (manifestar interés y motivación); y "poder hacer" (disponer de los medios y los recursos para ejecutar la actividad) (Canelón, 2012, p. 12).

\section{Modelo Comparative Excellence Framework (CEF)}

La necesidad de perfilar ese profesional de la comunicación y relaciones públicas como un sujeto facilitador de cambio en sus organizaciones, por vía de la medición y cualificación de la función, llevó a los promotores del estudio del LCM 2016 - 2017 a conectarlo con los fundamentos de la Teoría de la Excelencia postulada por Grunig, a través del Comparative Excellence Framework (Moreno, Wiesenberg, \& Verčič, 2015). Este modelo combina las reflexiones conceptuales sobre aplicación de revisión de calidad y reingeniería de procesos a la función, con autoevaluaciones de los comunicadores y análisis estadísticos.

En lo medular el CEF expresa que la Excelencia Comunicacional se sostiene sobre dos instancias y cuatro dimensiones: la influencia que la función de comunicación ejerce a lo interno de la organización (ser una unidad asesora y/o ejecutiva) y el desempeño que la misma realiza hacia el exterior (organización como actor comunicante) expresada en lograr el éxito y nivel de competencia. 
Si bien en la medición del LCM 2016 -2017, sólo un 16,8\% de los profesionales categorizó a su departamento de comunicación como "excelente" (Moreno, et al, 2017, p. 117), este segmento coincidió en atribuir el mayor peso a sus esfuerzos en "alinear la comunicación con los procesos corporativos, los ejecutivos y con el liderazgo", a la par que dio "más importancia a la RSC y el desarrollo sostenible".

Además de este modelo innovador CEF, ha de incorporarse en esta revisión la cualidad mediadora de la comunicación, aportada por la Teoría de los Sistemas Sociales de Nikklas Luhmann (1991). El acoplamiento individuo-organización es mediatizado por la comunicación, siendo ésta a su vez el instrumento para el relacionamiento, paso necesario en la construcción social. En dicho precepto, la comunicación es un acto netamente social, vinculado a un entorno, que tiene lugar entre sistemas con capacidad auto-referencial. Así conciencia y comunicación son elementos vinculados y codependientes. A tal premisa se suman elementos del pensamiento complejo, necesarios para la comprensión y desempeño en la sociedad actual, principalmente en gestión estratégica de las interacciones, manejo de la incertidumbre, la velocidad del cambio, así como la dimensión biológica del sujeto y de los sistemas sociales (Morin cit. por Zambrano, 2008).

\section{Comunicar, mediar e inspirar}

Dentro de esa perspectiva, el comunicador tiene una función mediadora, como sujeto de cambio. En los sistemas sociales, entre ellas la organización, el individuo en su relación con el otro (u otros) adquiere significancia como agente influenciador. Su singularidad es la base y meta de la sociedad, considerando las implicaciones de su acción social, es decir, la consecuencia de su conducta manifiesta, en un hacer interno o externo, con un sentido subjetivo (Zambrano, 2013). El sujeto autocomprendido o en uso de su inteligencia intrapersonal (Goleman, 1996; Gardner, H. 1983); potencia su rol mediador, con la inteligencia interpersonal e inteligencia social (Schvarsrtein, 2003) y la conciencia de cómo sus propios sesgos inciden en sus patrones de pensamiento y elección (Kahneman, 2011).

Como sujeto influyente hacia el interior de la organización, en la toma de decisiones de terceros y propias, el comunicador amerita cultivar sus propias cualidades de líder emocionalmente inspirado y triplemente enfocado: visión a lo interno, externo y en los demás (Goleman, 1996, p. 274). El cultivo de tales habilidades permeará finalmente a todos los niveles de la organización (Banbuer \& Clua de la Torre, 2014, p. 21). Esa es la base las organizaciones de mayor evolución en la sociedad actual.

Mediciones recientes en las organizaciones, como el estudio global How Report, exponen los logros de la transición del modelo de "gestión por obediencia ciega y sumisión informada" al estadio de autogestión (L.R.N, 2016), en el cual el liderazgo transformacional ${ }^{x i v}$ e inspirador es la clave para el progreso organizacional. El líder inspiracional se alinea con su realidad emocional interna, en sincronía con los valores comunes y sentires del grupo que conduce, logrando su motivación. Es sujeto capaz de amplificar su visión hacia las señales del entorno, mediante una actitud empática, comprendiendo el grado de afectación que puede causar en él. 
En ese relacionar estratégico, especialmente ante contextos signados por la incertidumbre y alta complejidad se requiere tener presente la inserción tanto del sujeto como de la organización en la dinámica de la sociedad informacional ${ }^{\mathrm{xv}}$ (Castells, 2001). La emergencia de una nueva cultura y condiciones tecnológicas ha implicado una reconfiguración del pensamiento humano, de la forma de relacionamiento en colectivo y de las fuentes de productividad y competitividad en las economías globales. Es la "lógica de la interconexión" que caracteriza a la sociedad-red conceptualizada por Castells como policéntrica, asociativa, contingencial, deslocalizada, proyectiva (Delgado-Flores, 2010). Se trata pues de una configuración virtual de la actuación del individuo en sociedad, sumando el entorno digital a los ámbitos de naturaleza y urbano, facilitando la creación de riqueza a partir de la interacción (Echeverría, 1999).

Sin embargo, el anhelo del comunicador en tanto líder mediador e inspirador de cambios en sus entornos, es aportar valor a la edificación de una ¿posible? sociedad de conocimiento, entendida por Delgado-Flores (2012) como la constituida por comunidades de habla, que practican la democracia deliberativa y generan economías del conocimiento en el entorno configurado por las Tecnologías de la Información y la Comunicación (TIC).

\section{Alfabetización en big data y algoritmos}

Alineado con lo anterior está la comprensión del fenómeno del big data ${ }^{\mathrm{xvi}}$, y la aún incipiente internalización del término en los DirCom latinoamericanos. Los autores del estudio LCM 2016-2017 tomaron como referencia conceptual las nociones de gran volumen de información y flujo de diferentes formas de datos, procedentes de diversas fuentes (externas e internas) en constante procesamiento, que producen nuevos conocimientos" (Gandomi \& Halder, 2015; Schoeck, cit. por Moreno, Molleda, Athaydes, Suárez, Herrera \& Álvarez, 2017).

Hablamos de una evolución vertiginosa de unidades de almacenamientos de datos en la World Wide Web que ha ido del Gigabyte ( $\mathrm{Gb}=1000$ megabytes), ubicándose hoy en el Terabytes $(\mathrm{TB}=1000$ gigabytes) para proyectarse en la inimaginable medida de Geopbyte (Geb = 1 Trillón de Terabytes). Dimensionar socialmente este complejo cyber fenómeno que ha impactado los patrones de producción, consumo y comportamiento social es de urgencia meridiana para carreras como la comunicación de excelencia.

En su vertiente positiva, incorporar la gestión de big data en los procesos comunicacionales entre organizaciones y sus públicos digitales, mejora la calidad de esta interacción en tiempo real, y por tanto potencia la predictibilidad de comportamientos de las audiencias y demarcando la toma de decisiones estratégicas. En su lado negativo, el manejar macro datos producidos por individuos, arriesga a que el comunicador deba inmiscuirse en la esfera privada de los llamados "prosumidores xvii" (Toffler, 1980), así sea bajo el consentimiento expreso de éstos, para perfilar su identidad digital en la que se definen hábitos de consumo, preferencias, aspectos de su psiquis y emocionalidad. De allí que, en tiempos de la posverdadxviii, el comunicador debe asumir un comportamiento ético en el manejo de big data, al ser débil la línea que conduce al intento de control y 
dominio social. Como bien demarca Carmen Ferré Pavia (2017, p.111), el comunicador ha de ser un promotor de la cultura data-conscious ${ }^{x i x}$.

El devenir de este fenómeno ha sido el centro de la llamada Cuarta Revolución Industrial (Schwab, 2015), con el aliciente de que los entornos digitales incentivan el big data más allá de lo divulgativo o persuasivo, para facilitar espacios de aprovechamiento inteligente de la información y co-creación de conocimiento. También se promueve la atención a las conversaciones digitales mediatizadas por la tecnología, más allá de las burbujas de información o cámaras de resonancia (Margetts, 2017), a la vez que se potencian soluciones. Un ejemplo: el Semáforo de Eliminación de Pobreza de Fundación Paraguaya (Burt, 2013).

En este tránsito hacia un paradigma de Sociedad del Conocimiento ideal, el comunicador ha de innovar también en su capacitación y formarse en tareas como organización y distribución contenidos (indexación de datos), el relacionamiento dialógico mediado, ser activo escucha de redes sociales de prosumidores, atender las brechas digitales culturales, impulsar políticas públicas de acceso y estudiar las identidades "líquida" (Delgado-Flores, 2012). Pero también de extrema importancia es conformar una dimensión ética a su perfil competencial, alineada con acciones regulatorias globales para preservar los derechos universales y la privacidad de los ciudadanos.

En el caso de Venezuela, desde la academia se han promovido iniciativas en manejo responsable de macrodatos. Es el caso del trabajo conjunto de la Universidad Católica Andrés Bello, el Instituto de Prensa y Sociedad de Venezuela (Ipys Venezuela) y la Organización No Gubernamental Transparencia con programas de capacitación en gestión de redes sociales, periodismo de datos, así como en defensa de acceso a la información.

\section{Metodología}

Como ya se indicó en la descripción general de la metodología en el artículo central del presente dossier sobre la edición 2016-2017 del Latin American Communication Monitor, los datos estadísticos para Venezuela se obtuvieron por vía de un cuestionario online autoadministrado (33 preguntas), por profesionales DirCom latinoamericanos y se emplearon escalas dicotómicas, nominales y ordinales para medición. La muestra resultante derivó de un estricto proceso de decantación de datos siguiendo estándares globales de este buró de investigación. En el caso venezolano se logró superar la prueba en cuanto cantidad y calidad de respuesta (sobre los 50 consultados), conquistando por primera vez su participación en los análisis comparativos (Moreno, et al, 2017, p.10).

El total de 53 encuestados DirCom venezolanos válidos depuró el equipo de analistas del LCM, constituyendo el 5,6\% de un universo de 946 cuestionarios completados por participantes de 17 países. Un hito local posible gracias al esfuerzo colaborativo de PostCom UCAB, el CIC-UCAB, la Red de Profesionales Comunicorpo, la agencia relacional Forum Media, así como el aporte significativo de individualidades 
del sector. Se conformó así una base de datos con los sujetos cuyo perfil se correspondía con el establecido en el diseño del estudio LCM; y se aplicó el instrumento mediante el contacto personalizado vía correo electrónico, las comunidades activas en redes sociales de agrupaciones profesionales y académicas, así como las llamadas telefónicas personalizadas.

A este procedimiento se sumó la investigación documental, para la identificación del estado del arte en la formación del comunicador organizacional venezolano, además de la precisión de los elementos contextuales tanto en el campo empresarial como el comunicacional que inciden en el desempeño profesional, o demandan de su atención. El análisis de esos datos y su contraste con los resultados regionales y locales del LCM, permitieron sentar las bases para un modelo de perfil competencial del comunicador organizacional venezolano acorde a los desafiantes tiempos.

\section{Discusión}

Dentro de las tendencias y desafíos explorados entre los comunicadores venezolanos, los que mayormente despertaron su atención fueron: la necesidad de aproximación a manejo de big data y algoritmos programados, las formas de relacionamiento (engagement) con los stakeholders y la articulación con influenciadores de redes sociales. Destacados también aspectos estratégicos de la función como la consultoría en toma de decisiones y la desfavorable brecha salarial que existe con el resto de Latinoamérica, ambos necesarios para llegar a niveles de excelencia.

\section{Demografía del caso venezolano}

Del análisis de datos se establece como perfil demográfico del comunicador venezolano presente en el LCM 2016-2017, al adulto joven con predominancia de figuración femenina (68\% son mujeres). Este indicador es reflejo de una tendencia entre egresados en comunicación social del país, orientados al campo de la comunicación publicitaria, organizacional y las relaciones públicas (Ver Figura 1)

Figura 1. Perfil demográfico

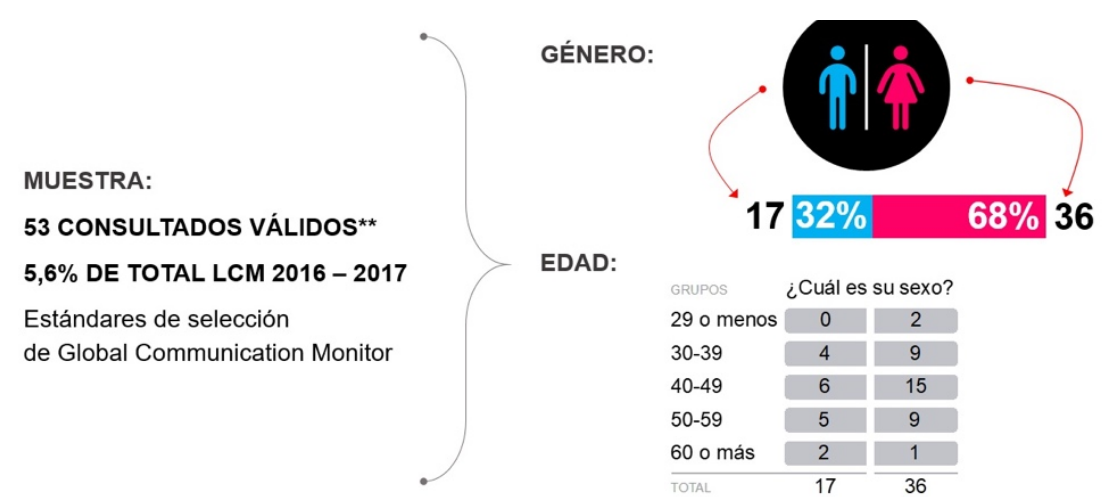

Fuente: Elaboración propia, bajo modelo de LCM 2016-2017

La inclinación de los profesionales se divide, en casi igual proporción, entre la labor como parte de un departamento de comunicación (49\%) y la prestación de servicios a través de agencias o en forma independiente (51\%), en un porcentaje superior a la media 
general del estudio general LCM 2016-2017. Si se toma en cuenta que las agencias también son empresas con propósitos de lucro, el 67,9\% de la muestra está inserto en el sector privado, mientras que la gestión comunicacional de lo público alcanza tan sólo un $9,4 \%$.

Se evidencia la combinación de trayectoria y sólida formación académica, y por tanto se les considera "migrantes digitales". Predominan los DirCom con más de 10 años de experiencia en el campo (75,4\%), estudios de cuarto nivel $(75,4 \%)$, y regentes de posiciones de autoridad en sus organizaciones como directores o jefes de equipo (74\%).

\section{Big data y algoritmos: importancia vs. uso}

Esta misma condición de experimentados profesionales en el ámbito gerencial, pero con necesidades de capacitación en alfabetización digital, explica el por qué el big data y los algoritmos se perfilaron como los mayores desafíos a vencer para la próxima década. En la comparación, Venezuela se ubicó de primera en este indicador, sobre los nueve países del balance comparativo.

De igual manera, los consultados muestran un alto conocimiento del término, al respaldar en un $83 \%$ la definición general de big data como Cantidad masiva de datos almacenados que proporcionen nuevos conocimientos que antes no estaban disponibles, unos 13 puntos por encima del promedio general de la consulta. Sin embargo, un buen segmento demuestra confusión (50,9\%) pues también le asoció al errado concepto de Interpretación de datos relevantes para la toma de decisiones estratégicas.

Esta condición desfavorable se ve reforzada si al 23\% que admitió no llevar en el presente actividades de big data, se suma $56,6 \%$ que obvió responder, para un obtener un $80 \%$. Tan sólo 19,6 \% reconoció haber implementado tecnología big data en sus procesos comunicacionales y 9,4\% que comenzaría actividades de macrodatos antes de que finalizar el 2017. No obstante, más de la mitad (58\%) reconoció su valor como habilidad competencial dentro de la función de comunicación al cruzar el 2019.

A partir del modelo de análisis cluster implantado en estudio global y que clasifica a los encuestados en cuatro subgrupos de acuerdo al grado de conocimiento sobre big data (ver Figura 2), el caso venezolano se comportó algo distinto a las cifras generales: en primer lugar se ubicaron los "Aspirantes" con 37\% (prestan atención al tema pero conocen poco), seguidos los "Informados" con 32,6\% (mayor atención y gran conocimiento), luego se ubican los "Transeúntes" con 26,1\% (alto conocimiento y bajo interés) y finalmente, los "Desinformados con tan sólo 4,3\% (ajenos al debate y desconocimiento amplio). Entretanto, en la muestra total, los "Informados" fueron los que ponderaron en mayor medida esta capacitación. 
Figura 2. Perfil del comunicador según conocimiento y seguimiento al debate sobre Big Data

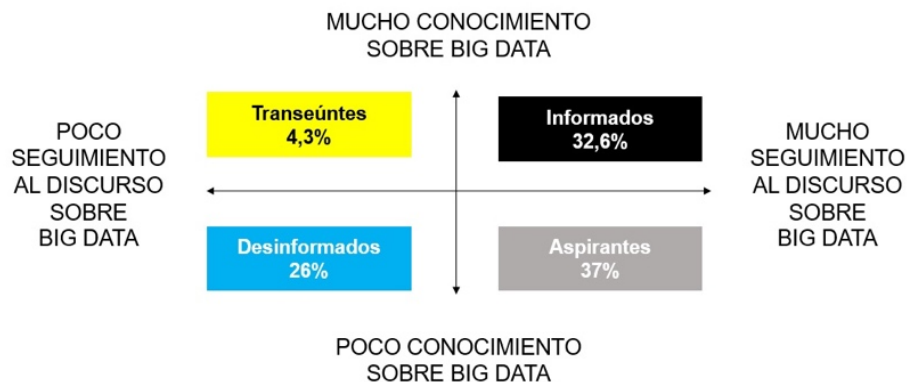

Fuente: Elaboración propia, bajo modelo de LCM 2016 - 2017

Por su parte, en lo que refiere a la instancia de directores y consejeros delegados (Chief Executive Officer, CEO) u otros en posición en toma de decisiones, la brecha entre presente y futuro es importante aunque menor (20 ptos). Más de la mitad (51\%) reconoció haber prestado atención "absoluta o muy poca" al debate de big data, y sin embargo 71\% de éstos le atribuye un sentido estratégico superior en las relaciones públicas.

En esta misma línea de autoevaluación sobre gestión comunicacional inteligente basada en big data, los DirCom venezolanos encuestados admitieron en mayor grado una "falta de habilidades analíticas" (57,5\%), "falta de habilidades técnicas" (47,7\%), así como, reconocieron una ausencia de soluciones de software que encajen con las necesidades de comunicación (40,9\%).

En cuanto al manejo de herramientas algorítmicas para la toma de decisiones y creación de contenidos, 96\% dictaminó que era entre importante y extremadamente importante. Lo cual denota una mayor confianza en la potencialidad de uso de tales aplicaciones para una efectiva gestión en marco de la revolución digital.

A pesar el alto peso que se atribuye a los algoritmos programados para distribución y búsqueda automatizada de contenidos, tan sólo un tercio de los consultados confirmó estar haciendo uso de estas herramientas, poniendo al descubierto una brecha tecnológica. Esta se acentúa en lo que refiere a las habilidades de creación y adaptación de contenidos, según la siguiente figura:

Figura 3. Herramientas algorítmicas en programas para distribución de contenidos

\begin{tabular}{rrr} 
EXCELENCIA FUNCIÓN DE LA COMUNICACIÓN & IMPORTANCIA & USO \\
\hline Distribución de contenidos. & $\mathbf{7 9 , 3} \%$ & $\mathbf{3 4 , 6} \%$ \\
\hline Adaptación de algoritmos en línea (motores de búsqueda). & $\mathbf{7 4 \%}$ & $\mathbf{3 4 , 6 \%}$ \\
\hline Toma de Decisiones. & $\mathbf{5 3 , 5 \%}$ & $\mathbf{3 4 , 6 \%}$ \\
\hline Creación contenido. & $\mathbf{6 5 , 5 \%}$ & $\mathbf{2 6 , 9 \%}$ \\
\hline Adaptación contenido. & $\mathbf{5 3 , 5 \%}$ & $\mathbf{1 5 , 3 \%}$
\end{tabular}

Fuente: Elaboración propia, bajo modelo de LCM 2016 - 2017 


\section{Prácticas y canales de la comunicación}

En la revisión de las prácticas ejercidas desde la función comunicación por los consultados, durante su tiempo productivo y en comparación con el resto de la muestra, tenemos que: el mayor lapso lo dedican a la dimensión operacional, en un porcentaje superior al promedio general. Le siguen las prácticas gerenciales y de articulación, las de armonización/mediación y finalmente las de consultoría a funciones estratégicas del negocio. Estas dos últimas expresadas en casi 10 puntos por debajo a la inmediata anterior, lo que denota el rol multitarea que ejerce el comunicador en detrimento de la calidad de la función.

Sin embargo, el segmento que respondió afirmativamente sobre su gestión de coaching a ejecutivos, indicó hacerlo aportándoles información y conocimiento valiosos para tomar iniciativas $(68,4 \%)$, orientándoles en manejo específico de desafíos comunicacionales $(66,7 \%)$ y en menor grado, habilitándoles para identificar la dimensión comunicativa que implican sus decisiones y atender por sí mismos tales demandas de la función.

Una de estas habilidades, cada vez más buscada y ejercida empíricamente, en más de los casos, por los directivos (inclusive DirCom), es ser portavoz de la organización vía social media; en otras palabras, ser además de mediador, un influenciador de los diálogos y temarios que en estos canales se están gestando. Esta tendencia fue de impacto en los resultados del LCM 2016 -2017 (Moreno, et al, 2017, p.92) y en el caso de Venezuela marcó sus picos especialmente en la medición de la autovaloración de habilidades de redes sociales. En este rubro, el mayor domino competencial de los consultados a su entender está en el diseño de estrategias $(58,5 \%)$, distribución de mensajes $(58,5 \%)$ e identificación de influenciadores que le darán credibilidad y viralidad a los mismos $(56,6 \%)$, ubicándose muy por encima del promedio del LCM. Lo cual se interpreta como síntoma de la acelerada conversión multimedia que vivió el sector comunicación en la última década en el país.

Figura 4. Autovaloración habilidades en social media

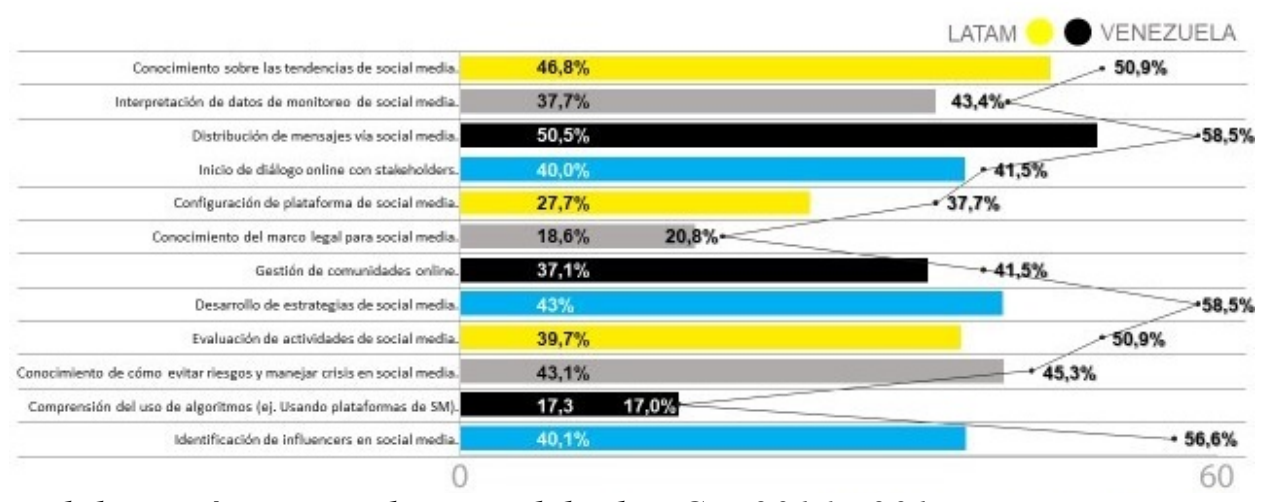

Fuente: Elaboración propia, bajo modelo de LCM 2016 - 2017

Entre las competencias donde estos comunicadores reconocen debilidad están la comprensión de uso de algoritmos automatizados (motores de búsqueda, análisis de data) con $17 \%$ y el dominio del marco legal que pauta uso de estas plataformas con $20 \%$. Sobre 
el rango normativo de redes sociales en Venezuela, anteriormente se indicó hoy es materia de debate y una importante excusa para que la élite gobernante pueda restringir y controlar desde el mencionado "régimen comunicacional" (Bisbal \& Aguirre, 2015).

Los comunicadores venezolanos no sólo articulan intensamente con los Social Media Influencers, sino que varios ellos forman parte de esta comunidad de aliados de las organizaciones. De allí destreza en la identificación de estos mediadores estratégicos del relacionamiento, siendo los atributos más valorados: su reputación personal $(89,6 \%)$, la importancia que dan al rol de SMI (86\%), la relevancia de temáticas y problemas que trata $(83,0 \%)$, la reputación de organización por él representada $(79,2 \%)$. Aspectos cuantitativos como grado de popularidad dado por el número de seguidores (alcance) y cantidad de mensajes emitidos (productividad), son menos considerados.

Figura 5. Rol del social media influencer

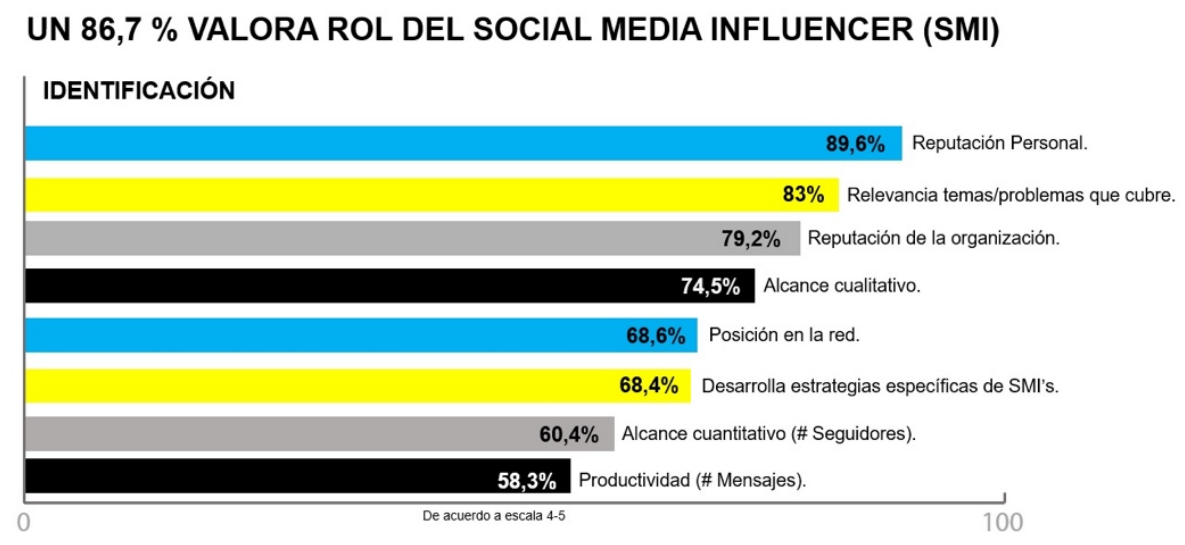

Fuente: Elaboración propia, bajo modelo de LCM 2016 - 2017

\section{Lo gerencial y lo vinculante de la función}

En el caso venezolano tanto la acción gerencial como la relacional, son consideradas como los otros dos grandes ejes temáticos de la función de comunicación, luego del protagonismo que se otorga a lo tecnológico, resumido en el gran desafío de “enfrentarse con la evolución digital y web social” (Moreno, et al, 2017, p.83).

En lo que refiere a competencias gerenciales, "fortalecer el rol de la función de comunicación para apoyar la toma de decisiones de los altos directivos" destaca $(37,7 \%)$ como meta hasta 2019 y son las agencias y consultores independientes los que mayormente orientados están a este logro. En esa misma línea está la valoración que dan a la vinculación de "las estrategias de la organización con la comunicación" (28,3\%). 
TEMAS ESTRATÉGICOS HASTA 2019| REVOLUCIONARIOS DE LA RED

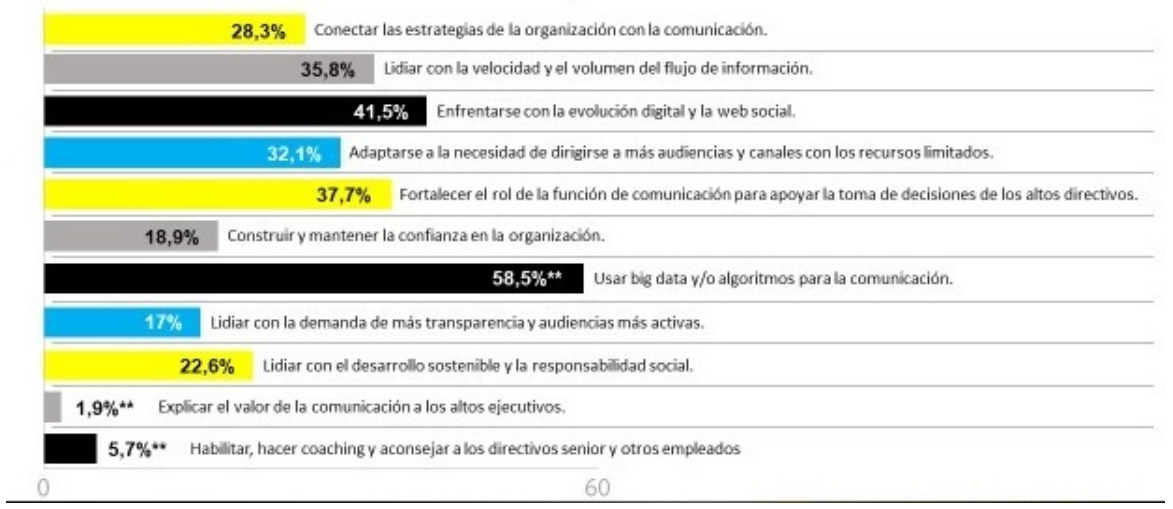

Fuente: Elaboración propia, bajo modelo de LCM 2016 - 2017

Sin embargo, funciones de la gerencia como explicar a directivos el valor estratégico de la comunicación y la consultoría ejecutiva, fueron ponderados muy por debajo ( $1,9 \%$ y $7,6 \%$ respectivamente), avizorando quizás que serán temas superados en tres años.

La vinculación con el entorno como tercer eje temático, es para los encuestados el de menor atención en la planificación estratégica para la siguiente década. Temas como "Lidiar con el desarrollo sostenible y la responsabilidad social", "Construir y mantener la confianza de la organización" y la demanda de transparencia ante audiencias más activas, no alcanzan en cada caso el $25 \%$ del respaldo entre los consultados.

En este sentido, hay entre los DirCom venezolanos una aproximación más afectiva al manejo del término de relación y compromiso con los grupos de interés (stakeholders), pues el 88,6\% asocia al engagement con "estar entusiasmado, orgulloso o vinculado", a partir del modelo de análisis propuesto en LCM 2016-2017 (Macnamara, 2016, cit. por Moreno, et al, 2017). Muy seguida está la dimensión cognitiva (estar interesado o sentirse involucrado) con un $86,7 \%$, la cual en la consulta general se ubica de primera. Situada de tercera está la participativa, donde siete de cada diez profesionales aprecian el grado de compromiso que genera "el deseo de colaborar o motivación para mejorar".

Esta tendencia de medir el vínculo y compromiso desde lo afectivo adquiere más fuerza cuando reconocen que los stakeholders comunican a terceros acerca de la organización $(64,2 \%)$ y le respaldan institucionalmente $(43,4 \%)$. El componente participativo de igual manera se expresa en el reconocimiento de trabajo conjunto entre grupos de interés y organización $(58,6 \%)$, mientras que el ámbito cognitivo se manifiesta al exaltar el diálogo de estas activas audiencias con la empresa (47,2\%). 


\section{EL ENGAGEMENT CON LOS STAKEHOLDERS}

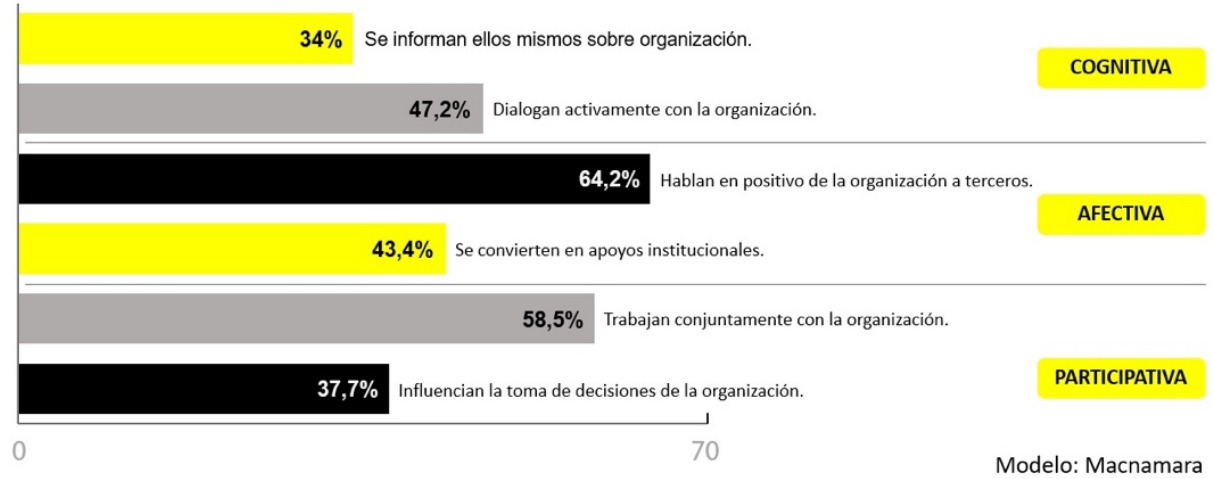

Fuente: Elaboración propia, bajo modelo de LCM 2016 - 2017

\section{Las competencias para una comunicación excelente}

De cara al 2020, estos comunicadores aspiran superar desafíos competenciales en las instancias de alfabetización tecnológica, habilidades gerenciales y fortalecimiento de la mediación, a fin de alcanzar niveles de excelencia en la función que dirigen. Si bien expresan la importancia de canalizar esfuerzos en capacitación para la acelerada convergencia digital global, tal como dominio de las redes sociales $(+10$ ptos), apps móviles $(+19$ ptos $)$, comunicación web $(+15$ ptos $)$, medios digitales $(+10$ ptos $)$, también reconocen la potencia de la comunicación no verbal $(+8$ ptos $)$ y la interpersonal o cara a cara ( +2 ptos).

Figura 8. Esfuerzos

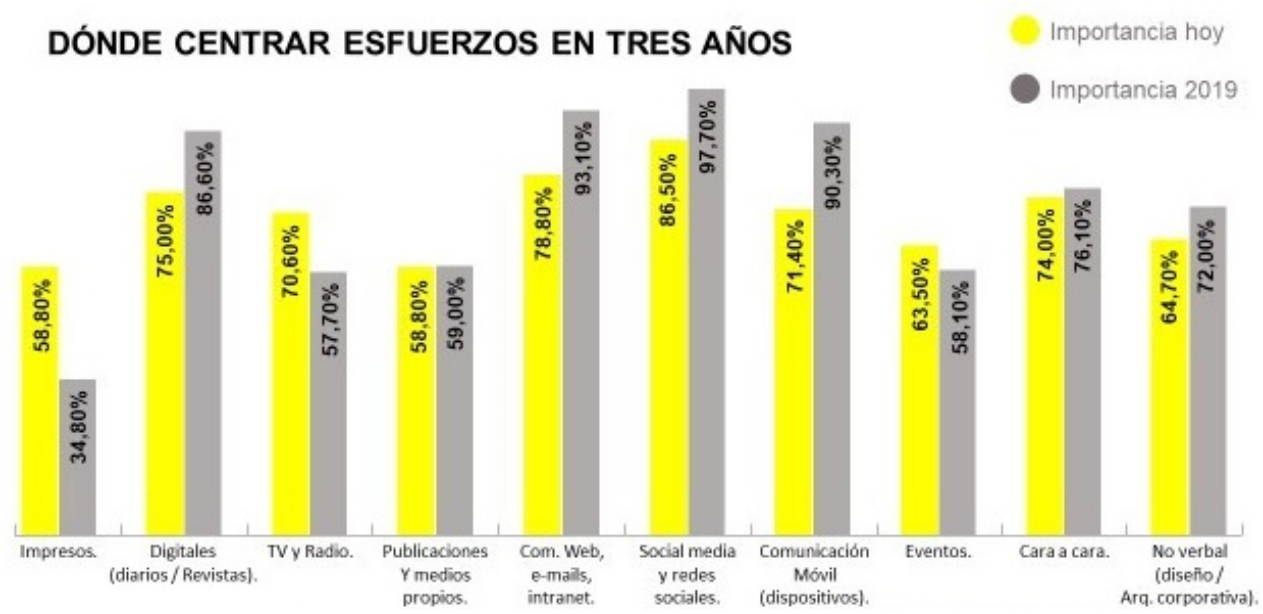

Fuente: Elaboración propia, bajo modelo de LCM 2016 - 2017

Según se aprecia en la Figura No. 8, también destaca la conciencia que tiene el grupo acerca del decrecimiento de los medios de comunicación tradicionales venezolanos, especialmente los impresos, proyectados a tres años como el tipo de comunicación de menor preferencia (-24\%) para implementar sus planes 
comunicacionales, probablemente como efecto del "régimen comunicativo" mencionado en nuestro apartado de contextualización.

Cuando estos datos son cruzados con el modelo CEF (Moreno, et al, 2017), se aprecia que la función de comunicación de altos estándares será aquella cuyo capital humano dialogue vía social media y redes sociales, promueva la interacción en línea al igual que la cara a cara con sus grupos de interés, articule desde las plataformas móviles a la par que recurra a la comunicación basada en el diseño y la arquitectura corporativa (no verbal) y asegure presencia en medios audiovisuales.

Figura 9. Departamentos de comunicación

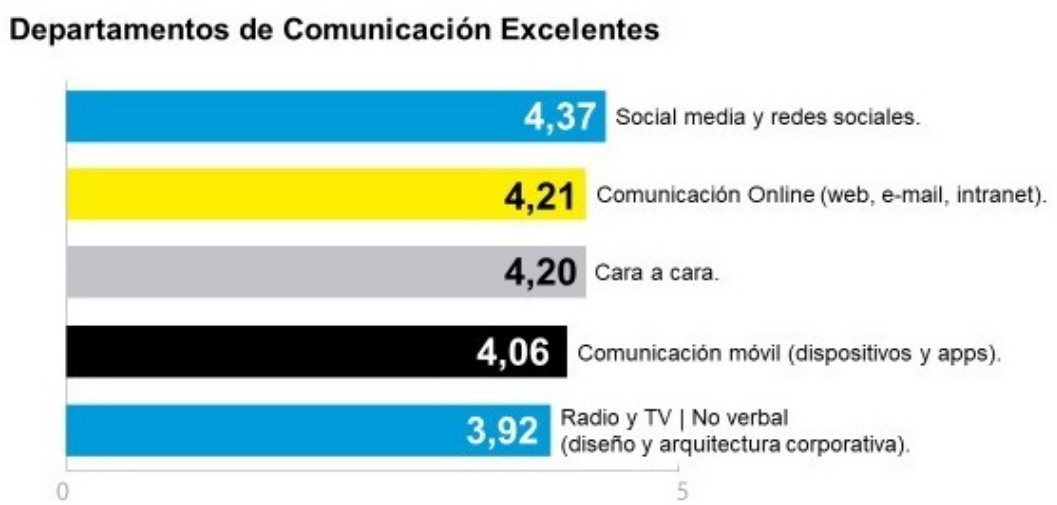

Fuente: Elaboración propia, bajo modelo de LCM 2016 - 2017

En esta autoevaluación, al igual que la realizada por el total de los DirCom consultados en LCM 2016 - 2017, se certificó que de lograr incrementar estos niveles de excelencia de la función comunicación en un lapso de tres años, aumentaría su grado de influencia tanto asesora como ejecutiva dentro de la organización, así como el peso de su desempeño hacia el entorno medido por el éxito de ese engagement dialógico y por su competitividad frente a sus organizaciones pares.

En el sondeo, estos profesionales reportaron querer mejorar habilidades de gestión asociadas a la administración, tales como manejo de recursos financieros y de recursos humanos, establecimiento de estructuras y control de procesos, todas calibradas apenas unas décimas por encima de la media de 3 (Escala de 1 a 5). Entretanto las propias comunicacionales como posicionamiento estratégico, liderar personas o grupos y relacionamiento obtuvieron un valor por encima de 4. De allí que el nivel general de las habilidades del comunicador venezolano, para este estudio, se ubicó en 3,81 ptos, superando a grandes de la región como México $(3,75)$, Brasil $(3,67)$ y Argentina $(3,55)$ y ubicándose tan sólo unas décimas menos que Colombia $(3,85)$.

No obstante, esta positiva autocalificación de habilidades de los DirCom venezolanos frente a sus pares de la región, contrasta ampliamente con la brecha salarial evidente frente a las otras naciones de esta segunda edición del LCM. Un 83\% de la muestra confirmó contar con un salario base menor a los 10.000,00 dólares anuales, cuando tres cuartas partes de los consultados latinoamericanos reportaron estar ganando por debajo de los 30.000 dólares anuales. El profesional venezolano, de alta jerarquía, 
devenga un tercio del salario promedio anual establecido para el resto de los 16 países latinoamericanos participantes ${ }^{\mathrm{xx}}$.

Se comienzan a identificar profesionales en posiciones laborales o de consultoría independiente establecidas para proveer productos y servicios a distancia (remota). La brecha salarial y la expansión de las fronteras (Páez, 2015) ha abierto una ventana de oportunidades a los comunicadores, dado lo atractivo del diferencial remunerativo para los contratantes o empleadores, en comparación con otros mercados.

\section{Conclusiones}

El análisis e interpretación de los datos correspondientes a Venezuela del estudio Latin American Communication Monitor en su segunda edición, juntamente con los elementos propios del entorno venezolano, conducen a formular los siguientes planteamientos. Sin ser concluyentes, permiten establecer una base para la comprensión del estado del arte en el ejercicio de la comunicación en las organizaciones que operan en Venezuela.

Las tendencias de los resultados del estudio en Venezuela, en sus diferentes ejes de conocimiento, en su mayoría se corresponden con los resultados globales del LCM 2016-2017, especialmente en lo que refiere a innovación de la gestión con big data, redes sociales y la llamada revolución digital. Pese a cualquier tipo de rezago presente en el país, el profesional venezolano avizora estos desafíos y se alinea con sus homólogos de la región. Por tanto, reconoce su no manejo de habilidades de alfabetización digital.

Por tanto, se confirma la necesidad de equilibrar lo que el DirCom establece como su desafío competencial más relevante (la brecha digital) y la dinámica relacional subyacente como consecuencia del entorno operacional para las empresas venezolanas, al igual que las tendencias globales que convocan la transparencia y la confianza. Habría que explorar -porque en los resultados no se precisa) si esa preferencia de enfocar esfuerzos en lo digital guarda relación directa con la consolidación de vínculos con los stakeholders.

De allí la necesidad de renovar en los comunicadores en formación el entusiasmo por tendencias del emprendimiento socialmente responsable, que superen la gestión asistencial-reactiva, alcanzando un nivel transformador que incluya el modelo de valor compartido (Porter \& Kramer, 2011).

Apuntando a esta meta de re-concebir la articulación entre sociedad venezolana y desempeño corporativo, el comunicador en rol mediador puede valerse de las soluciones tecnológicas para fortalecer la esfera participativa frente a la afectiva, siendo estos relacionamientos los predominantes identificados en toda la muestra del Monitor Latinoamericano (Macnamara, 2016, cit por Moreno, et al, 2017).

El comunicador responsable ha de entender la complejidad de la brecha digital existente en Venezuela entre grupos de interés (stakeholders) pues además de un nivel socioeconómico, implica otro educativo que afecta la esfera de la economía del conocimiento (Delgado-Flores, 2015, p.8). En este sentido, ese elemento empático e 
inspiracional (formación en liderazgo) debe estar presente en su desempeño individual como en el de la función a la hora de promover emprendimientos sociales de impacto en la construcción de credibilidad y sustentabilidad.

Igualmente, esa cualidad de motivador debe expresarla el profesional a lo interno de la organización, para defender el sentido de inteligencia de la unidad de comunicación. Seguir ampliando la acción influyente de los DirCom dentro de la actuación de los consejos directivos de las empresas, a la par que acompañando a sus líderes en el suministro y manejo de información cualitativa derivada del análisis de big data y los algoritmos programados para redes sociales, que produzca soluciones consensuadas junto a sus clientes, comunidades y usuarios.

La gestión de liderazgo también se manifiesta en plano subjetivo, al observar que casi $80 \%$ (alto y muy alto) ejerce inspiración ante "personas o grupos", lo que denota autocomprensión de su condición de elemento armonizador ante la complejidad social. Intensificar en este valor cognitivo intrapersonal, sumando las otras dos inteligencias referidas por Schvarsrtein (2003), la interpersonal y la social, potenciaría en los comunicadores venezolanos su efecto de actor conciliador entre un empresariado relegitimado y una sociedad transformada.

Pero llegar a ese estadio, en el caso venezolano resulta casi utópico al confirmar las mencionadas brechas de capacitación y salarial que padece el profesional frente a sus pares de Latinoamérica. Se trata de una amplia desventaja competitiva, que al igual que otros campos del saber, ha sumado comunicadores a la diáspora venezolana. Un revés socioeconómico que asoma su lado positivo, cuando se asocia a la expansión de conexiones con otros países, dando como resultado la emergencia de una tipología de comunicadores asociada al teletrabajo. De allí que la alfabetización tecnológica adquiera una relevancia instrumental indispensable para canalizar favorablemente nuevas oportunidades.

Entretanto, para atender el complejo, volátil e incierto contexto nacional, el profesional de la comunicación en formación debe privilegiar aquellas ofertas educativas y capacitadoras que hilvanen de manera equilibrada ejes de conocimiento, complementarios y propiciadores de sinergia, que refuercen su rol mediador, responsable, vinculante, dentro de los sistemas sociales. Y esta inclusión abarca también a los comunicadores en ejercicio dentro del sector público, el cual contó con baja participación en este primer caso venezolano del LCM y a pesar de ser actor clave en el crecimiento y evolución del mencionado Estado-comunicador. De allí que resulte de capital importancia incorporarlo al debate la dimensión moral del profesional, frente a un posible desempeño como agente de propaganda (Molleda, 2015).

Y finalmente, regresando al cuestionamiento inicial, dirigido al nexo entre estado de los departamentos de comunicación y las vías para su transformación en excelentes, se proponen a continuación los ejes de un perfil competencial correspondientes a mallas curriculares de cuarto nivel. Este aporte involucra la perspectiva de sociedad del conocimiento, con sentido de diálogo entre disciplinas que combinen alfabetización 
digital, consultoría estratégica, mediación inteligente junto al desempeño responsable y ético (Delgado-Flores, 2012, p.239).

\section{Recomendaciones}

\section{Aproximación a los ejes competenciales del DirCom venezolano}

El desarrollo del perfil competencial para el DirCom venezolano, de cara a los próximos 10 años implica el manejo de teorías innovadoras, en distintos campos epistemológicos: neurociencia, pensamiento complejo, fenomenología, ciberpragmática, valor compartido, entre otros. Se potencian a su vez con los avances tecnológicos informáticos manejados responsablemente y contando como referente al Comparative Excellence Framework. Será la ética el elemento transversal en todo este entramado para garantizar una toma de decisiones (propias y de terceros) sostenibles.

Tal modelo de formación contempla cuatro dimensiones del conocimiento como base para un modelo perfectible de perfil competencial para el director de comunicación esquematizado en la Tabla No.1:

Cognitiva: referida al dominio de las teorías necesarias para el desempeño del DirCom en su autoconocimiento sobre su rol gestor en la organización.

Analítica: conjunto de habilidades necesarias para la organización e interpretación de datos de primer y segundo orden.

Técnica: Compendio de habilidades digitales e informáticas clave para los procesos comunicacionales.

Conativa: Destrezas para la operacionalización de las tres dimensiones anteriores, con criterios de excelencia e innovación. 
Tabla 1. Propuesta de perfil competencial del DirCom venezolano

\begin{tabular}{|c|c|}
\hline $\begin{array}{l}\text { Ámbito } \\
\text { temático }\end{array}$ & Objetivo \\
\hline $\begin{array}{l}\text { Alfabetización } \\
\text { digital }\end{array}$ & $\begin{array}{l}\text { Garantizar el manejo inteligente de } \\
\text { big data, algoritmos, métricas y } \\
\text { semánticas digitales en marco de la } \\
\text { revolución digital para la } \\
\text { construcción de equipos de } \\
\text { Comunicación de Excelencia. } \\
\text { Fortalecer el debate sobre manejo } \\
\text { inteligente de big data y algoritmos } \\
\text { en redes sociales en ámbitos } \\
\text { académicos y profesionales, } \\
\text { elevando el nivel a esferas cognitivas } \\
\text { y normativas. }\end{array}$ \\
\hline
\end{tabular}

Competencias

Habilidad para proponer, manejar y comprender desarrollos y soluciones tecnológicas (Apps, software, programación) que den respuesta a las necesidades de vinculación interna y externa con los stakeholders, de conocimiento y comprensión del entorno, así como impulso a innovaciones sociales.

Capacidad de obtener y organizar data que permita identificar o crear información relevante para la toma de decisiones en los líderes de las organizaciones.

Habilidad para utilizar herramientas tecnológicas que apoyen la toma de decisiones en el ámbito de gestión y manejo de recursos (técnicos, financieros $\mathrm{y}$ humanos).

Inteligencia Potenciar su autoconsciencia como intrapersonal sujeto influyente en los líderes organizacionales y en los procesos del engament con grupos de interés.
Habilidad para el ejercicio del coaching y gestión de cambio con los líderes, voceros organizacionales y talento estratégico.

Potenciación del carácter y autoconfianza sobre la base de la autocomprensión de las preferencias y del rol como sujeto mediador y motivador del cambio en organizaciones y contextos específicos.

\begin{tabular}{ll}
\hline Alfabetización & Impulsar y desarrollar apertura \\
sistémica & mental a la transdiciplinariedad, así \\
& como la innovación y el pensamiento \\
& integrador.
\end{tabular}

Incentivar desde la función, creativas formas de inclusión relacional, para aquellas comunidades de usuarios aisladas y sin conectividad digital (reducir la brecha cognitiva y tecnológica).

Fortalecer de igual manera, construcción de confianza y el aprendizaje compartido.

Asumir a las redes sociales como una importante herramienta para identificar fenómenos sociales y la escucha activa.
Visión y procura del diálogo productivo, empático y co-creador con actores de otras disciplinas.

Fomento proactivo de vínculos para la cocreación y la cooperación bajo un esquema ganar-ganar.

Búsqueda e impulso a soluciones comunicacionales que incentiven $y$ consoliden los vínculos con los grupos de interés clave rezagados en materia cognitiva y tecnológica.

Incentivar el intercambio e internalización de saberes derivados de las prácticas

\footnotetext{
Productor de Desarrollar contenidos con criterios Narrativas: Creación y divulgación de conocimientos de relevancia y pertinencia contenidos alineados con los distintos perfiles establecidos de acuerdo con las caracterizaciones de sus grupos de interés
} 
Conocimiento: Capacidad de enlazar experiencias e impulsar la documentación de prácticas.

\begin{tabular}{lll}
\hline Ético & $\begin{array}{l}\text { Promover la discusión académica y } \\
\text { profesional sobre la dimensión ética } \\
\text { que encierra manipular e interpretar }\end{array}$ & $\begin{array}{l}\text { Conciencia de alcances y limitaciones en la } \\
\text { manipulación, interpretación y divulgación } \\
\text { grandes volúmenes de datos. Ser }\end{array}$ \\
$\begin{array}{l}\text { agente activo en la cultura del data- } \\
\text { conscious. }\end{array}$ & $\begin{array}{l}\text { Habilidad de realizar aportes significativos en } \\
\text { la reflexión del cuerpo directivo ante el } \\
\text { impacto de sus decisiones en la sociedad. }\end{array}$ \\
& $\begin{array}{l}\text { Impulso a la responsabilidad moral en los } \\
\text { procesos de engagement. }\end{array}$ \\
& $\begin{array}{l}\text { Fomento de la transparencia en el gobierno } \\
\text { corporativo }\end{array}$
\end{tabular}

Fuente: elaboración propia

La propuesta representa un punto de partida, mediante un cuerpo de saberes estratégicos para el fortalecimiento de los DirCom en Venezuela, vistos en su ideal rol de agente mediador, influyente y en procura de la excelencia, en un contexto de alta complejidad. Es una tarea que corresponde evaluar y validar mediante los procesos académicos propios de la revisión curricular. Sin embargo, la velocidad de los cambios en la sociedad del Siglo XXI conduce a proponer la flexibilización e integración de las formas y estructuras que permitan dar respuesta a las demandas de los DirCom y sus organizaciones, con un sentido oportuno, no sólo en Venezuela sino en el resto de Latinoamérica. 


\section{Bibliografía}

Alarcón García, G. \& Guirao Mirón, C. (2013). El enfoque de las capacidades y las competencias transversales en el EEES. Historia y Comunicación Social. (18), pp 145-157.

Recuperado de: https://revistas.ucm.es/index.php/HICS/article/viewFile/44318/41876

Alvarado, B. (2016, 30 de agosto). Fedecámaras respetará derecho de trabajadores a marchar el $1 S$. Portal de Noticias Globovisión. Recuperado de: http:/globovision.com/article/fedecamaras-unas-350-mil-empresas-han-cerradoen-esta-ultima-decada

Bisbal, M. (2012a). El Estado-comunicador y sus comunicaciones. ¿Comunicaciones de servicio público? Ponencia presentada en el I Encuentro de Organizaciones Sociales (EOS). Caracas: Universidad Católica Andrés Bello (UCAB).

Bisbal, M. (Abril - Junio 2012b). Venezuela en la encrucijada de sus comunicaciones. Las dimensiones comunicacionales del régimen. Revista Comunicación (158). Caracas: Centro Gumilla. Recuperado de http://gumilla.org/biblioteca/bases/biblo/texto/COM2012158_12-23.pdf

Bisbal, M. et al. (2015). Encrucijadas de la comunicación en Venezuela. $40^{\circ}$ aniversario de la revista Comunicación del Centro Gumilla Caracas: Bi\&Co Editores.

Burt, M. (2013). The "Poverty Stoplight" Approach to Eliminating Multidimensional Poverty Business, Civil Society, and Government Working Together in Paraguay. Innovations. Global Youth Economic Opportunities Conference. Boston: MIT

Canelón, A. (2012). Un perfil de competencias para el Comunicador Organizacional. Reflexiones desde el Postgrado en Comunicación Social de la Universidad Católica Andrés Bello. En: Relaciones Públicas: el diálogo de las organizaciones. Sevilla: AIRRPP. Recuperado de: http://airrpp.org/descargas/Actas_VII_Congreso_AIRP_Sevilla2012.pdf

Castells, M. (2001). La era de la información I. La sociedad-red. México: Siglo XXI.

CONATEL. (2017). Informe de Cifras del Sector II Trimestre 2017. Telecomunicaciones. Comisión Nacional de Telecomunicaciones. Recuperado de: http://www.conatel.gob.ve/informe-cifras-del-sector-tercer-trimestre-2016/

D’ELIA, Y. et al. (2006). Las Misiones sociales en Venezuela: una aproximación a su comprensión y análisis. Caracas: ILDIS.

Delgado-Flores, C. (2015). La sociedad del conocimiento como modelo de desarrollo. Una aproximación al caso venezolano. Revista Comunicación (171). pp107 -115. Caracas: Gumilla Recuperado de: http://www.gumilla.org/biblioteca/bases/biblo/texto/COM2015171-172_107115.pdf 
Delgado-Flores, C. (2012). Educación para la Sociedad del Conocimiento en Venezuela En: Ugalde, L. et al. Educación para transformar el país. Seminario CERPE UCAB , pp. 221-244) Caracas: UCAB. Recuperado de: http://www.cerpe.org.ve/tl_files/Cerpe/contenido/documentos/Actualidad\%20Ed ucativa/0\%20-\%20Libro\%20ETP\%20-\%20Version\%20publicacion.pdf

Echeverría, J. (1999). Los señores del aire. Telépolis y el tercer entorno. Barcelona: Destino.

EFE Futuro. (2017, 08 de febrero). El relator de la ONU de privacidad denuncia la omnivigilancia en el mundo. Ipys Venezuela. Recuperado de: http://ipysvenezuela.org/2017/02/08/relator-la-onu-privacidad-denuncia-laomnivigilancia-mundo/

Ferré Pavia, C. et al. (2014). El uso de las redes sociales: ciudadanía, política y comunicación. La investigación en España y Brasil. Bellaterra: Institut de la Comunicació, Universitat Autònoma de Barcelona. ISBN: 978-84-942706-0-4

Flores, I. (2017). La formación del periodista 2.0 en las universidades venezolanas. ComHumanitas: revista científica de comunicación, (8), pp. 42-60. Recuperado de: http://www.comhumanitas.org/index.php/comhumanitas/article/view/124/pdf

Fundación Centro Gumilla. (2011). III Estudio sobre valoraciones en Venezuela. Recuperado de: http://gumilla.org/democracia3.

García Canclini, H. (1999). El consumo cultural en América Latina. En: Sunkel, G. et al. El consumo cultural en América Latina: construcción teórica y líneas de investigación. Chile: Ediciones Convenio Andrés Bello. Recuperado de https://perio.unlp.edu.ar/catedras/system/files/el_consumo_cultural__garcia_canclini.pdf

Gardner, H. (1995). Inteligencias múltiples, la teoría en la práctica. Barcelona: Planeta.

Gardner, H. \& Davis, K. (2014). La generación app. Cómo los jóvenes gestionan su identidad, su privacidad y su imaginación en el mundo digital. Barcelona: Paidós.

Goleman, D. (1995). La inteligencia emocional. Barcelona: Editorial Keirós.

Goleman, D. (2013). Focus. Desarrollar la atención para alcanzar la excelencia. Barcelona, Editorial Keirós.

González, M. et al. (2016). Encuesta Condiciones de Vida del Venezolano. Caracas: Universidad Simón Bolívar. Recuperado de: http://www.rectorado.usb.ve/vida/node/59

Institute for Economics \& Peace. (2017). SDG16 Progress Report. A comprehensive global audit of progress on available SDG16 indicators. Australia Recuperado de: http://visionofhumanity.org/app/uploads/2017/09/SDG16-Progress-Report2017.pdf 
Global Progress Initiative. (2016). Índice de Progreso Social. Recuperado de: https://www.socialprogressindex.com

Institute for Economics \& Peace. (2017). Global Peace Index. Australia. Recuperado de: http://visionofhumanity.org/app/uploads/2017/06/GPI17-Report.pdf

Kahneman, D. (2012). Pensar rápido, pensar despacio. Barcelona: Random House.

Kramer, M. \& Porter, M. (2011). Creating Shared Value. Boston: Harvard Business Review (89. January/February).

Luhmann, N. (1991). Sistemas Sociales: Lineamientos para una teoría general. México. Universidad Iberoamericana/Alianza Editorial.

L.R.N. Corporation (2016). The How Report. Recuperado de: https://content.1rn.com/featured-perspectives/how-report

Magrett, H. (2017, 05 de enero). Por supuesto que las redes sociales están transformando la política. Pero no se las puede culpar del Brexit y Trump. World Economic Forum. Recuperado de: https://www.weforum.org/es/agenda/2017/01/por-supuesto-que-lasredes-sociales-estan-transformando-la-politica-pero-no-se-las-puede-culpar-delbrexit-y-trump/

Miller, T. \& Kim, A. (2016). Index of Economics Freedom. The Heritage Foundation Recuperado de http://www.heritage.org/index/

Mirvis, PH. \& Googins, B. (2006). Stages of Corporate Citizenship: A Developmental Framework. Boston: Center of corporate citizen of Boston College. Recuperado de:

https://www.researchgate.net/publication/3228435_Stages_of_Corporate_Citize nship

Morin, E. (1988). Introducción al pensamiento complejo. Barcelona: Gedisa.

Molleda, J. (2015, 31 de marzo). Las relaciones públicas amenazadas de convertirse en propaganda: el caso Venezuela. Portal Runrun.es. Recuperado de: http://runrun.es/opinion/195791/las-relaciones-publicas-amenazadas-de-convertirse-enpropaganda-el-caso-venezuela.html

Moreno, A., Wiesenberg, M., \& Verčič, D. (2015). Excelencia en la Gestión de Comunicación. Análisis de los Departamentos de comunicación en España mediante el Comparative Excellence Framework . Revista ComHumanitas, 7(2), pp.1-15.

Moreno, A., Molleda, J. C., Athaydes, A. \& Suárez, A. M. (2017). Latin American Communication

Monitor 2016-2017. Excelencia en comunicación estratégica, trabajo en la era digital, redes sociales y profesionalización. Resultados de una encuesta en 17 países. Bruselas : EUPRERA. 
Pasquali, A. (2016, 30 de mayo). El comunicador social hoy en Venezuela es un pequeño héroe de la cotidianidad. Noticiero Digital Recuperado de: http://www.noticierodigital.com/2016/05/antonio-pasquali-el-comunicadorsocial-hoy-en-venezuela-es-un-pequeno-heroe-de-la-cotidianidad/

Paéz, T. (2015). La voz de la diáspora venezolana. Madrid: Editorial La Catarata.

Pwc Venezuela. (2017). V Encuesta de Responsabilidad Social en Venezuela. Caracas.

Redacción Runrunes. (2015, 13 de marzo). 450 mil empresas han desaparecido en Venezuela en los últimos 16 años. Portal Runrun.es. Recuperado de: http://runrun.es/nacional/inbox/192637/450-mil-empresas-han-desaparecido-envenezuela-en-los-ultimos-16-anos.html

Diario Oficial de la Unión Europea (2016, 27 de abril). Reglamento (UE) 2016/679 del Parlamento Europeo y del Consejo. Recuperado de: http://www.agpd.es/portalwebAGPD/canaldocumentacion/legislacion/union_eur opea/reglamentos/common/pdfs/Reglamento_UE_2016679 Proteccion_datos_DOUE.pdf

Schwab, K. (2016). La Cuarta Revolución Industrial. Madrid: Editorial Debate.

Schvarsrtein, L. (2003). La Inteligencia Social de las Organizaciones. Buenos Aires: Paidós,

Toffler, A. (1982). La Tercera Ola. Barcelona: Plaza y Janés.

Tuning América Latina. (2007). Informe Final Proyecto Tuning-América Latina. En: Reflexiones y perspectivas de la educación superior en América Latina. Bilbao: Publicaciones Universidad Deusto. Recuperado de: http://tuning.unideusto.org/tuningal.

Vásquez, M. (2014, 04 de agosto). Escuelas de comunicación social análogas para un periodismo cada vez más digital. MediaLab, UCAB. Recuperado de: http://apps.ucab.edu.ve/medialab/blog/2014/08/04/periodismo-digital-vsescuelas-analogas/

Venamcham. (2017). Indicadores RSE. Presentación llevada a cabp en el XVII Simposio de Responsabilidad Social Empresarial, Caracas, Venezuela.

Zambrano, X. (2008). Aproximación al pensamiento complejo para una comprensión del vínculo humano. En: J.A. Silva \& J. Graterol (Comp.) Gerencia y Condición Humana. Cuadernos de Postgrado (28), pp. 97-131. Caracas: Fondo Editorial Tropykos - UCV.

Zambrano, X. (2013). Responsabilidad Social Empresarial y Comunicación: relación para la transformación social. Temas de Comunicación (26), pp.65-90 Caracas: Universidad Católica Andrés Bello. 


\section{Notas}

1 Xiomara Yamil Zambrano es Doctora en Ciencias Sociales (UCV) con amplia trayectoria en Comunicación Organizacional, Responsabilidad Social, activismo empresarial en Venezuela. Es Investigadora Asociada del CIC-UCAB y docente de esta casa de estudios. Ha trabajado en programas educativos e iniciativas para la formación y capacitación de emprendimiento y valor compartido (DirCom XYZ Consultores). Ha impulsado proyectos de investigación (social y comunicacional), así como productos y procesos comunicacionales corporativos multimedia e impresos, incluyendo comunidades virtuales. Especializada en certificación de Norma SG21:2008 para la Gestión de RSE del Foro internacional para la evaluación de la Gestión Ética (Forética).

2 Claudia Furiati Páez es Comunicadora Social venezolana (UCV) con especialización en Comunicaciones Integradas (UNIMET). Es Investigadora Asociada del CIC-UCAB con dilatada carrera en el ámbito de la gestión en comunicación relacional, innovación en narrativas periodísticas transmedia y mediación en redes sociales (DirCom Forum Media). Responsable de campañas de comunicación relacional estratégica, gestión de programas de RSE e Innovación para emprender. Maneja la plataforma de redes sociales Festilectura, orientada al incentivo del hábito y la comprensión lectora entre comunidades de nativos digitales.

3 Ángeles Moreno es doctora con premio extraordinario por la Universidad Pontificia de Salamanca y Profesora Titular en la Facultad de Comunicación de la Universidad Rey Juan Carlos (Madrid). Ha enseñado e impartido cursos en diversas instituciones educativas en Europa y América. Es Directora Ejecutiva de la European Public Relations Research and Education Association, es miembro activo del Grupo de Estudios Avanzados en Comunicación (GEAC) y participa y dirige proyectos de investigación de la Unión Europea, la European Public Relations Research and Education Association (EUPRERA), el Plank Center de la Universidad de Alabama, la University of Florida y el MICINN. Forma parte desde hace diez años del equipo de investigación del mayor estudio sobre la Gestión de Comunicación en el mundo, el European Communication Monitor y es directora del proyecto Latin American Communication Monitor. Sus trabajos han sido premiados internacionalmente por la International Communication Association, la Public Relations Society of America y la European Public Relations and Research Association.

\footnotetext{
${ }^{i}$ Se denominan "Misiones" a los programas sociales creados por el gobierno venezolano en el año 2003 para cubrir en forma masiva carencias en materia de salud y educación. Luego se incorporaron las asistencias en vivienda, alimento y registro civil. Su sistema formal de gobernanza está bajo directrices de la Presidencia de la República e implica un significativo esfuerzo de propaganda y fidelización ideológica del régimen.
}

ii El puntaje general de Venezuela es 27,0 ocupando el lugar 179 de 180, sólo por encima de NorCorea. Tal posición le otorga la calificación de economía "reprimida".

iii El empleo remoto o teletrabajo es una modalidad no presencial, propia de los sistemas de producción y servicios que pueden operacionalizar total o parcialmente sus procesos a través de entornos virtuales, mediante el uso de plataformas y herramientas digitales.

${ }^{\text {iv }}$ Denominación acuñada por Bisbal (2016) para acentuar la explícita vocación hegemónica y omnipresente del régimen comunicativo que signa al Estado venezolano.

${ }^{v}$ Progresivamente la ciudadanía ha ido ocupando espacios comunicacionales, principalmente mediante el uso de las redes sociales, para dar respuesta al vacío informativo que dejan los medios censurados o autocensurados. Este fenómeno ha sido especialmente notorio en momentos críticos, tal como lo son las protestas de calle.

vi Ley de Responsabilidad Social de Radio y TV vigente desde 2008 y Ley contra el Odio, la Intolerancia y por la Convivencia Pacífica aprobada en noviembre de 2017 y que regula los contenidos en redes sociales. En ambos casos se observa un manejo semántico que conecta con la moral y el desempeño ético ciudadano.

vii Se toma el concepto de consumo cultural aportado por la escuela latinoamericana de Estudios de la Cultura, encabezada por el sociólogo Néstor García Canclini: "conjunto de procesos de apropiación y usos de productos en los que el valor simbólico prevalece sobre los valores de uso y de cambio". (Canclini, 1999: p.89). 


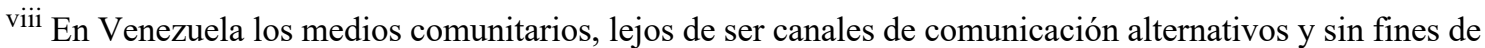
lucro para el empoderamiento de la sociedad civil, constituyen un circuito de incidencia directa en la acción de calle y el quehacer cotidiano de las comunidades, para la preservación de la causa chavista y bajo la tutela presidencial.

ix La gestión de la comunicación organizacional requiere, cada vez más, un enfoque transdiciplinario e integrador. El comunicador al ejercer liderazgo o co-crear junto otros profesionales, necesita articular saberes y dar respuestas oportunas, asertivas e innovadoras a las organizaciones.

x El independiente Proyecto Alfa Tuning América Latina 2004- 2007 generó una metodología pedagógica y disciplinaria consensuada en el subcontinente, basada en competencias comparables y reconocibles entre los programas académicos de Educación Superior.

${ }^{x i}$ La Maestría en Comunicación Social - Opción en Comunicación Organizacional- de la UCAB actualizó su pensum en 2011, centrando sus contenidos en la concepción de la organización como microsociedad (sistema abierto), integrada con entornos complejos y dinámicos.

${ }^{\text {xii }}$ Hacemos referencia a la noción de pensamiento sistémico propuesta tanto por Peter Senge y otros autores contemporáneos que se han ocupado de estudiar la capacidad del pensamiento humano para identificar y comprender la correlación entre los modelos cibernéticos y la dinámica social.

xiii Se alude a la naturaleza del vínculo entre la organización y sus partes interesadas (stakeholders), en tres vertientes: cognitiva, afectiva o colaborativa.

xiv Según el estudio How Report (L.R.N., 2016) en el mundo actual coexisten tres arquetipos de organizaciones productivas, a modo de estadios evolutivos: obediencia ciega, sumisión informada y autogestión. Este último es el más avanzado y se corresponde con un sistema social autogestionado, identificando entre sus características el desempeño de líderes alentados por valores, aspiraciones de trascendencia y alto compromiso.

xv La sociedad informacional es la descrita por M. Castells para catalogar a toda forma de organización social emergida a partir de la revolución de las tecnologías de la información, siendo la acción del conocimiento sobre sí mismo su principal fuente de productividad.

xvi Las autoras sostienen concordancia con el concepto utilizado por el estudio Latin American Communication Monitor, en cuanto a definir este fenómeno en términos de bases de datos de un tamaño y complejidad que requieren un abordaje y herramientas especiales para su procesamiento y utilidad.

xvii Este acrónimo fue acuñado en 1980 por el teórico de la Economía del Conocimiento, Alvin Toffler, al agente social que fusiona cualidades de consumidor y productor, pues disfruta de bienes y/o servicios generados por sí mismo.

xviii La posverdad es un neologismo derivado del término "post-truth", aceptado desde 2017 por el Diccionario Real Academia Española para calificar actos de "distorsión deliberada de una realidad que manipula creencias y emociones, con el fin de influir en la opinión pública y en actitudes sociales".

xix La investigadora da visibilidad con esta terminología a las iniciativas que activan y fortalecen el rol de agente corresponsable del usuario, en tanto ciudadano, en el manejo y protección de sus datos e identidad en la red.

xx Brecha por demás, que, al momento de la redacción de este trabajo, se ha ampliado exponencialmente al entrar en fase de hiperinflación la economía venezolana. 